\title{
The Concept of "Mandala" and ASEAN: A Comparative Analysis on Southeast Asian Region Formation
}

\author{
Samuwel Chaminda Padmakumara \\ South Asian University, New Delhi
}

\begin{abstract}
How and why regions are constituted? What make regions? These questions are answered by various approaches to the study of regions in multiple ways. Somehow, what has been missing from these approaches is a systematic and contextual analysis on region formation processes while connecting regional history to their contemporary formation. Therefore, this paper adopts the historical concept of "mandala" in pre-colonial Southeast Asia and connects it to Association of Southeast Asian Nations (ASEAN) in order to offer a comparative analysis on Southeast Asian region formation. The "mandala" systems as patterned political structures, advance an idea of unique political behavior among units in the region and are useful to understand ASEAN and its institutional structures. A comparative review of these two dimensions points to a systematic and contextual analysis on Southeast Asia as a region. On the basis of such comparative understanding, the paper reveals that this joint analysis based on historical and institutional aspects of the region claims Southeast Asia to be more of an ideationally constructed region.
\end{abstract}

Keywords: The concept of "mandala", ASEAN, Pre-colonial Southeast Asia , Ideational framework

\section{Introduction}

Scholarly work on the idea of region offers multiple understanding and explores a number of ways in which regions have been constituted. Similarly, there is relatively little consensus among the scholars with regard to how and why regions are formed. More or less, the existing scholarly work offer different analyses on region formation, but what has been missing from their focus is systematic and contextual understanding as to why and how regions are constructed. As regions are constructed in different ways, it is important to focus on the key dimensions involved in their formation. At the same time, it is pertinent to closely examine how the interplay of such selected dimensions is significant to widen and broaden the existing knowledge about the region. As here identified, different regions require different conceptual frameworks to comprehend their region formation and what constitute them as regions may also vary from one case to another.

As the lines of what constitute regions really matter to understand regions comprehensively, this study has $\mathrm{i}$ dentified two major constitutive sources by which Southeast Asian region formation could be contextually and systematically perceived. For this purpose, the study incorporates a two-dimensional analysis that focus on the concept of "mandala" as a historical and ASEAN as an institutional dimension. Beyond the conventional understanding of Southeast Asia, the study primarily relies on these two constitutive elements to broadly illuminate how Southeast Asia has been constructed as a region. In the case of Southeast Asia, it is assumed that historical and institutional structures are highly relevant, and are potential in providing a broader and mutually constitutive analysis for its region formation.

In general, the concept of "mandala" explains the unique style of intra- regional relations during precolonial Southeast Asia. This concept has range of meanings from spiritual to political domain, but this study is primarily concerned with its geo-political proposition. From a geo-political sense, "mandala" is a term employed to denote traditional Southeast Asian political formations". In Wolters' explanation "the map of 
Southeast Asia which evolved from the prehistoric networks of small settlements and reveals itself in historical records was a patchwork of often overlapping 'mandala's, or circles of kings"[1]. Indeed, these cooperative political structures advocate certain unique political behavior among the units in a common space and are useful in various ways to comprehend Southeast Asian region formation.

At another level, ASEAN appears to be one of promising dimensions to serve such a joint analysis. The contemporary ASEAN proves that it has progressed as an institutional setting to a greater extent. Concurrent to this institutional success, its visionary schemes also have undergone various changes to the date. Specifically, what some scholarly engagements evidently reveal is ASEAN has changed the course of their regional integration initiatives and therefore, it will be hard to claim that ASEAN still proceeds on its original path and continues to focus merely on economic integration[2]. Despite, these objective transformations " what sets the organization apart from many other regional institutions is its own process of decision- making, typically referred to as the "ASEAN Way'[3].

In this respect, it is reasonable to think that contemporary ASEAN is broadly linked with a normative agenda that constructively shape the interactions among its members. Generally, the existing scholarship has often viewed ASEAN as a mere institutional setting, rather investigating how it can serve as a constitute source of region formation. Similarly, they have paid little attention on the ways in which it can be conceptually connected to a model of patterned historical engagements existed in the same region. At this very point, it is pertinent to conduct a conceptual inquiry on how ASEAN constitutes a region while exploring the possibilities of connecting it to ideational values coming from "mandala"systems. Of course, this way would provide a different conceptual outlook for our analysis.

In the rest of this paper, firstly the historical concept of "mandala" will be introduced by looking at its different meanings and definitions while illuminating why the concept of "mandala" is significant to understand Southeast Asia as a region. Secondly, how ASEAN advocates an idea of a common space will be discussed by primarily focusing on its normative characteristics. Then, the third section will shed light on comparative understanding about the idea of " mandala" and ASEAN while particularly treating them as spatial categories. Finally, the study reveals on which common basis these two dimensions jointly establish Southeast Asia as a region and explore new conceptual basis for analyzing Southeast Asia as constructed region.

\section{The Concept of "Mandala"}

As explained by Rosita Dellios "the Sankrit term "mandala" represents a significant tradition of knowledge in Southeast Asia. Normally considered a religious diagram used as a meditational aid, the "mandala" is the first and foremost construction"[4]. From the same traditional perspective Maggie Grey also argues that "the "mandala" then is traditionally constructed as a site for the metaphoric realization of universal concepts deemed necessary for the further development of human character" [5]. In spite of its spiritual significance, the concept of "mandala" provides rich accounts on a distinguished political culture in pre-colonial Southeast Asia. The idea was adopted by $20^{\text {th }}$ century Western historians (most notably, O.W. Wolters 1968, 1982: and I.W Mabbett 1978 from ancient Indian political discourse as means of avoiding the term 'state' in the conventional sense"[6]. In the political context, " "mandala" describes a kingdom as well as the circle of kingdoms in ancient India and pre- colonial Hindunised Southeast Asia” [7]. As further explained by Rosita Dellios, “ as a spiritual -political expression, it referred to the configuration of earthly power along cosmic lines. Moreover, "places and royal cities in traditional India, China and Southeast Asia depicted the heaven -earth cosmogram of the divinely imbued king at the centre of a square" [8]. Despite this cosmological interpretation, Amitav Acharya explains that the "mandala"system helped to establish a common pattern of intra-regional authority" [9]. Within this scheme of understanding, the concept of "mandala" can be identified as a possible repository of patterned and unified political practices which had been existed during pre-colonial Southeast Asia. While the concept of "mandala" refers to a wider array of political interactions and coordination of power relations between a 
powerful center and periphery, it demonstrates how pre-colonial Southeast Asia has been fabricated by unique political structures and establishes an idea of a common space.

What the existing literature suggests is searching for homogeneity in ethnic, geographical, linguistic and religious factors to analyze South Asia region formation is a difficult task. Instead of such approach, it would be instructive to look at some particular features that can provide unique understanding about the regional history of Southeast Asia. In this sense, the concept of "mandala" can be a very useful analytical tool to explore some unique regional features of Southeast Asian history. As argued by scholars, what is common in the Southeast Asian history can be best answered by the concept of "mandala" while treating it as a historical source of region formation. Therefore, this study primarily focus on the concept of "mandala" as an analytical tool that can conceptually connect to institutional formation of modern Southeast Asia.

\section{ASEAN and Southeast Asian Region Formation}

ASEAN was not of course the first regional cooperative venture in which Southeast Asian nations had participated [10]. In a general sense, what the existing literature on the regionalism suggests is, in the aftermath of the Second World War, there has been a wave of regional movements in different parts of the world. Mostly these attempts have searched for peace and stability through different regional mechanisms. Despite several unsuccessful initiatives, some attempts have made progress to a significant extent [11]. Specifically, in the context of Asia-Pacific region, regional settings such as Southeast Asia Treaty Organization (SEATO) and the Asian-Pacific Council were proven to be insufficient due to various reasons. Unlike NATO, SEATO had no independent mechanism for obtaining intelligence or deploying military forces and also it suffered from lack of credibility. Hence, it was disbanded in 1977[12]. In the case of Asian-Pacific Council (ASPAC), which was a grouping of anti-communist states, was also not able to reach its goals .Therefore, it was ultimately disintegrated in 1972[13]. The failure of these intuitional settings waived a path for another initiative called Association of Southeast Asia (ASA) that "was set up and involved the union of three countries: Malaya, Thailand and Philippines" [14]. Then, the inadequacy of ASA necessitated the creation of another regional organization called MAPHILINDO compromising Malaysia, Philippines and Indonesia [15]. Somehow, the failure of this institutional body led to another successful regional scheme through which members states sought more favourable conditions for better regional cooperation. This resulted the emergence of ASEAN; the Association of Southeast Asian Nations which consisted Philippines, Thailand, Malaysia and Singapore at the time of its inception. With the initiatives of these five nations, ASEAN came into its existence on August 8, 1967. Then, "in the following decades, Brunei Darussalam, Viet Nam, Lao PDR, Myanmar and Cambodia joined the Association. Under umbrella of ASEAN, these members intend to achieve the goal of ensuring peace and stability in their home region in parallel to the promotion of economic growth and social development' [16]. While concerning such broader objectives to accelerate economic growth, social progress and cultural development, members have unanimously agreed to comply with the principles set forth in the UN Charter and to adhere to the rule of Law in practice [17]. Despites the intra-regional tension which made the previous process sluggish, some political transformations that took place during the mid 1960's in the region has created more favourable atmosphere for the establishment of ASEAN.

Further, these political changes have laid a strong foundation for ASEAN to closely look at the possibilities availed for a deeper regional cooperation and also this aim has been vividly reflected in the ASEAN Declaration or Bangkok Declaration signed in 1967. As indicated by the ASEAN Declaration, parallel to the aim of achieving regional economic and social progress, the initiators have urged for identifying historical and cultural ties that could sustain the proposed cooperative scheme for the region. For instance, the preamble of the ASEAN Declaration clearly advocates that "the cherished ideals of peace, freedom, justice and economic well-being are best attained by fostering good understanding, good neighbourliness and meaningful cooperation among the countries of the region already bound together by ties of history and culture' [18]. While recognizing the importance of historical and cultural commonalities in harmonizing regional interests, 
the declaration further emphasizes the need of ensuring the stability and security from external interference. In considering these intuitional developments and the visionary values embedded in the organization, it is reasonable to argue that ASEAN advocates a common regional space in Southeast Asia.

\section{4. "Mandala" and ASEAN as Spatial Models : Comparative Perspectives}

The idea of spatiality has significant conceptual leverage upon understanding regions. On the other hand, some scholarly work suggests that spatiality has both physical and cognitive meanings. The idea of space plays a significant role in understanding how and why regions are formed. In general, what the scholarly work suggests is that the spatiality is understood and interpreted in many different ways. From the perspectives of geography, "spatial representations are linked to core spatial concepts of location, region, distribution, spatial interaction and scale that constrain and representations of observations. All are discrete physical entities" [19]. Although, the general trend is to perceive the spatiality in such material ways, the concept of "mandala" can be considered as a special category of spatial representation. Despite the geographical or physical understanding to space, "mandala" is reasonably fitting to a cognitive way of looking at a spatial dimension which has been built upon a symbolic value system.

Somehow, the concept of "mandala" is largely demanded by the cognitive way of understanding about precolonial Southeast Asia and advances coherent understanding about the space in a different manner. Hence, the concept of "mandala" demonstrates a particular pattern of political relations and provides a distinct spatial model for understanding Southeast Asian regional space. The special feature of this spatial model that has been derived from pre-colonial Southeast Asian "mandala" system is that, under such system the space had been perceived as a product of symbolic political interactions. Therefore, under "mandala" systems, the idea of territorial rigidity or 'bounded space' in understanding spatiality becomes less important. Instead, the concept of "mandala" offers a form of fluid and inter-subjective understanding about the space of Southeast Asia. However, under "mandala" systems, it is not impossible to claim a coherent spatial organization in terms of patterned political interactions.

While the concept of "mandala" demonstrates properties of a spatial category to conceptualize Southeast Asia, it is equally important to understand how ASEAN as an institutional setting invokes the idea of spatiality. In a very specific sense, ASEAN has institutionalized a particular geographic area as a region and claim its members to have a regional consciousness within a defined geographical setting. Therefore, ASEAN as an institution has demarcated a particular territory and members are given certain regional autonomy over the region. In this sense, ASEAN has organized the space of Southeast Asia in both physical and ideational sense To elaborate, the members of ASEAN are sovereign nations and thereby, the space of Southeast Asia can be defined as an amalgamation of sovereign nations. In other words, the contemporary space of Southeast Asia is a collection of sovereign bodies and therefore certain geo-political demarcations make Southeast Asia as a common space. On the other hand, the spatiality of Southeast Asia has been more formalized and legalized though the institutional structures of ASEAN and offer substantial certainty on the spatiality of the region. As far as the pattern of the spatial organization is concerned, it can be argued that, ASEAN members are horizontally connected to the space of Southeast Asia via a common geo-political conviction. This results a wider array of intra-spatial relations and leads to certain behavioral prescriptions with and within the membership. Similarly, such hulking interactions within the region and patterned behavior of members that are maintained and facilitated by ASEAN institutional instructions are largely useful in legitimizing our understanding about a common space in Southeast Asia. As discussed in this section, these two dimensional analysis offers a broader conceptual venue for understanding the region formation in Southeast Asia in both contextual and systematic manners. This contention can be further sustained by a comparative discussion.

From a comparative perspective, "mandala"'is more likely to provide cognitive understanding while ASEAN is advancing understanding more of a geographically fixed acumen about space in Southeast Asia. Somehow, this is not the assertion to a fully disagreement. With the diffusion of ASEAN norms, it is reasonable 
to accept that, ASEAN also has ideationally integrated the space of Southeast Asia to some visible extent. In this sense, it can be argued that ideational factors are supplementary to understand the spatiality in Southeast Asia through ASEAN. Although the concept of "mandala"systems were considered to be fluid, they are able to constitute a sense of organized space through a set of patterned and recurring interactions that had been taken place within the system. Besides this fact, the space of pre- colonial Southeast Asia has been ordered by the "mandala"'system in two directions. One is vertical way in which the center has been devotionally attributed. The other way is the center - periphery relations that followed a horizontal pattern over the space. In contrast, ASEAN has horizontally organized the space of Southeast Asia by its constant interactions with its members which are essentially horizontally demarcated as sovereign nations in the region. The inference , therefore , the concept of "mandala"'advances constructive meaning to the space of pre-colonial Southeast Asia while ASEAN constitutes more geographically fixed space being supplemented by the ideational factors.

\section{Conclusion}

In this analytical setting , it can be summarized that, both concept of "mandala" and ASEAN are able to jointly analyze the formative structures of Southeast Asian region formation in a more contextual and systematic manner. These two dimensions largely advance a constructive understanding about Southeast Asian region formation and share some common ideational traits. Hence, it is reasonable to argue that historical and institutional aspects are more capable and optimal to analyze how modern Southeast Asia has been constructed as a region.

Although, the concept of "mandala" and ASEAN offer different understanding about the spatiality, what the above the analysis particularly indicates is that there is a common ideational thread that could interwove these dimensions to comprehend Southeast Asian region formation. Therefore, it is important to understand that both these dimensions constitute ideational basis for perceiving Southeast Asia as a common space. More specifically, shared meanings, ideas, norms and loyalties are largely present as ideational factors in both dimensions. The "mandala" systems offer unique style of intra -regional affairs and advocates an idea of a common space in Southeast Asia. In the same manner, ASEAN also convince its member to adopt a common behavioral approach through its normative framework and organizes Southeast Asia as a common space. Somehow, this study does not claim that contemporary Southeast Asia with its institutional formation is absolutely conformed to pre-colonial "mandala" systems. Instead, this study argues that understanding the way in which the space of Southeast Asia has been organized by these two dimensions offer us a common framework to connect past and present in analyzing Southeast Asian Region formation. Finally, it also argues that a joint analysis on the concept of "mandala" and ASEAN offers powerful conceptual basis for constituting Southeast Asia as a region.

\section{References}

[1] O.W Wolters , History, Culture, and Region in Southeast Asia perspectives , New York: Southeast Asia Program Publications , 1999 , p. 27

[2] Eduard Alan Bulut "Community -Building in ASEAN ?: A Theoretical Approach to Regional Institutionalization in Southeast Asia" Turkish Journal of Politics , vol. 3,1, Summer, 2012 , pp.53-66

[3] Katja Weber “ ASEAN : A Prime Example of Regionalism in Southeast Asia”, European Union Miami Analysis, vol. 6,5 April , 2009 , pp.1-19

[4] Dellios, Rosita, "'mandala': from sacred origins to sovereign affairs in traditional Southeast Asia" (2003).CEWCES Research Papers. Paper 8. [Online]. Available : http://epublications.bond.edu.au/cewces_papers/8

[5] Maggie Grey "Encountering the 'mandala': the mental and political architectures of dependency" Culture 'mandala': The Bulletin of the Centre for East-West Cultural and Economic Studies, vol. 4, 2 2001, pp.1-13

[6] Ibid 
[7] Rosita Dellios "Globalisation and the 'mandala': Software for the millennium" Culture 'mandala': The Bulletin of the Centre for East-West Cultural and Economic Studies, vol. 4, 1 2000, pp.1-10

[8] Ibid

[9] Amitav Acharya "Imagined Proximities :The Making and Unmaking of Southeast Asia as a Region , Southeast Asian Journal of Social Science, vol. 27,1 1999 , pp. 55-76 https://doi.org/10.1163/030382499X00192

[10] Roger Arvine, The Formative Years of ASEAN : 1967-1975 Understanding ASEAN , UK : Macmillan , 1982, p. 8

[11] Eduard Alan Bulut , Turkish Journal of Politics ,p . 54

[12] Katja Weber , European Union Miami Analysis , p. 4

[13] Ibid

[14] Mohamad Faisol Keling atl "The Development of ASEAN from Historical Approach" Asian Social Science , 7,7, 2011, pp.169-189

[15] Ibid

[16] Eduard Alan Bulut, Turkish Journal of Politics 3,1 , p.55

[17] Ibid

[18] ASEAN Declaration, Bangkok , 1967

[19] Susan M. Walcott "Mapping from a Different Direction: 'mandala' as Sacred Spatial Visualization" Journal of Cultural Geography, vol. 23,2, 2006 , pp.71-88

https://doi.org/10.1080/08873630609478223 